\title{
Simulation of Orissa Super Cyclone (1999) using PSU/NCAR Mesoscale Model
}

\author{
U. C. MOHANTY ${ }^{1 \star}$, M. MANDAL ${ }^{1}$ and S. RAMAN ${ }^{2}$ \\ ${ }^{1}$ Centre for Atmospheric Sciences, Indian Institute of Technology, Delhi, Hauz Khas, New \\ Delhi-110 016, India; ${ }^{2}$ Department of Marine, Earth and Atmospheric Sciences, North Carolina \\ State University, NC 27695-8208, USA
}

(Received: 17 October 2001; accepted: 25 October 2002)

\begin{abstract}
In this study a non-hydrostatic version of Penn State University (PSU) - National Center for Atmospheric Research (NCAR) mesoscale model is used to simulate the super cyclonic storm that crossed Orissa coast on 29 October 1999. The model is integrated up to $123 \mathrm{~h}$ for producing 5-day forecast of the storm. Several important fields including sea level pressure, horizontal wind and rainfall are compared with the verification analysis/observation to examine the performance of the model. The model simulated track of the cyclone is compared with the best-fit track obtained from India Meteorological Department (IMD) and the track obtained from NCEP/NCAR reanalysis. The model is found to perform reasonably well in simulating the track and in particular, the intensity of the storm.
\end{abstract}

Key words: super cyclone, track, intensity, best-fit, mesoscale model

\section{Introduction}

Tropical cyclones are one of the most devastating and deadliest meteorological phenomena. Strong winds, torrential rainfall and storm surges are the three major elements of tropical cyclone disasters. The Bay of Bengal is a potentially energetic region for the development of cyclonic storms (Gray, 1968). At an average 3-4 cyclonic storms, 2-3 of severe intensity hit east coast of India in a year. The storms that hit east coast of India or Bangladesh during post-monsoon period are most devastating (De Angelis, 1976). Casualty figures associated with such storms in recent past are 200,000 and 131,000 in Bangladesh in 1971 and 1991; 10,000 and 1,000 in 1977 and 1990 in Andhra Pradesh (India). Timely and reasonably accurate predictions of track and intensity of these storms are therefore of great importance.

Numerical Weather Prediction (NWP) models are now being widely used for prediction of tropical cyclones both in operational and research modes. Barotropic models developed at the beginning of NWP era are still in use in some of the tropical cyclone forecasting centers. Hurricane Research Division (HRD), USA model (De Maria et al., 1992) and Bureau of Meteorology Research Center (BMRC) Australia model (Holland et al., 1991) are the two recent models performing well

\footnotetext{
^ Author for correspondence. E-mail: mohanty@cas.iitd.ernet.in
} 
in tropical cyclone forecast. With the availability of supercomputing facility, most of the leading NWP centers are using high-resolution regional and global models for prediction of tropical cyclones. Some of the recent baroclinic regional models in use for prediction of tropical cyclones are: Typhoon Model (TYM) for western North Pacific (Iwasaki et al., 1987), Quasi-Lagrangian Model (QLM) for USA (Mathur, 1991), BMRC Model for Australia (Puri et al., 1992), Taiwan Model (Chen et al., 1995) and Geophysical Fluid Dynamics Laboratory (GFDL) model (Kurihara et al., 1993, 1995). Recent developments towards improvement of global models have yielded improved tropical cyclone forecasts. Krishnamurti and Oosterhof (1989) reported systematic improvement in the formation and motion of the storms with increasing horizontal resolution of the model. The improvements in tropical cyclone life cycle and track forecast are summarized by Krishnamurti et al. (1993).

In India, Mandal et al. (2003) showed systematic improvement in prediction of track and intensity of tropical cyclones with increasing horizontal resolution of a limited area model. Prasad (1990) and Prasad et al. (1992, 1997), proposed a scheme for generating synthetic vortex in initializing a primitive equation limited area model for tropical cyclone forecast. Gupta et al. (1997) showed the impact of insertion of bogus vortex in the model analysis on the prediction of tropical storms over Indian seas.

The super cyclone that crossed Orissa coast on 29 October 1999 was the most intense tropical cyclone in the history of Orissa after the False Point cyclone of 1885. It was as intense as Bangladesh cyclone of 1977 that caused death of 200,000 people. In this study, PSU/NCAR mesoscale model (MM5) is used to simulate the storm with appropriate physical parameterization schemes. The model has already showed some skill in simulating hurricanes (Karyampudi et al., 1998) including some at high resolution (Liu et al., 1997, 1999; Braun and Tao, 2000). The objective of the present study is to evaluate the performance of the model towards simulation of track and intensity of the super cyclonic storm.

After introduction, a short description of the model is given in Section 2. Synoptic features and experimental design with data used are described in Section 3. Results of the model simulation and analysis maps are presented in Section 4 and finally conclusions in Section 5.

\section{Model Description}

In this study a non-hydrostatic version of the MM5 modeling system developed at Pennsylvania State University (PSU)/National Center for Atmospheric Research (NCAR) by Anthes, Warner, Ying-Hwa, Kuo and their colleagues is used. MM5 is a primitive equation limited area model. It has both hydrostatic and non-hydrostatic versions. A terrain-following vertical co-ordinate system (sigma) is used with a specific presentation in the non-hydrostatic version. Instead of usual pressure, 
a reference-state pressure is used to define the sigma coordinate. A constant reference-state and a perturbation are defined as:

$$
\begin{aligned}
& p(x, y, z, t)=p_{0}(z)+p^{\prime}(x, y, z, t), \\
& T(x, y, z, t)=T_{0}(z)+T^{\prime}(x, y, z, t),
\end{aligned}
$$

where $p$ and $T$ are pressure and temperature, and subscript zero and prime represent the reference-state and perturbation. The reference-state temperature profile is based on an idealized hydrostatic equilibrium and is specified by the equation:

$$
T_{0}=T_{s 0}+A \ln \left(\frac{p_{0}}{p_{00}}\right),
$$

where, $p_{00}$ is sea-level pressure taken to be $1,000 \mathrm{hPa}, T_{s 0}$ is the reference temperature at $p_{00}$ taken to be $299 \mathrm{~K}$ (varies within the range $280 \mathrm{~K}$ to $300 \mathrm{~K}$ with the season), and $A$ is a measure of lapse rate taken to be $50 \mathrm{~K}$, representing the temperature difference between $p_{00}$ and $p_{00} / e=367.88 \mathrm{mb}$. The vertical coordinate is then defined as:

$$
\sigma=\frac{p-p_{t}}{p_{s}-p_{t}}
$$

where $p_{s}$ and $p_{t}$ are surface pressure and pressure at the top of the model (10 Pa in this study) for the reference-state. The reference-state surface pressure, which depends only on the terrain height, can be derived from Equation (1) using the hydrostatic relation:

$$
Z=-\frac{\mathrm{RA}}{2 g}\left(\ln \frac{p_{0}}{p_{00}}\right)^{2}-\frac{\mathrm{RT}_{s 0}}{g}\left(\ln \frac{p_{0}}{p_{00}}\right) .
$$

This equation is quadratic in $p_{0}$ and can be solved if $Z$, the terrain height is known. The reference pressure of the model sigma levels are then calculated as:

$$
p=\left(p_{s}-p_{t}\right) \sigma+p_{t}
$$

The main prognostic variables in the model are pressure perturbation $p^{\prime}$, three velocity components $(u, v, w)$, temperature $T$ and specific humidity $q$. Model equations are written in flux form and solved numerically using Arakawa B grid. Leapfrog time integration scheme with time splitting technique is used in model integration. In time splitting technique, the slowly varying terms are integrated in time with longer time step and the terms giving rise to fast moving gravity waves are integrated with shorter time step.

The most useful feature of MM5 model is its flexibility in the sense that many options are user specified. The model can be used in various applications by simply 
Table I.

\begin{tabular}{ll}
\hline Model & $\begin{array}{l}\text { Fifth-Generation Penn State/NCAR Mesoscale Model (MM5) } \\
\text { version } 2.12\end{array}$ \\
\hline Dynamics & Non-hydrostatic with three-dimensional Coriolis force \\
Main prognostic variables & $u, v, w, T, p^{\prime}$ and $q$ \\
Map projection & Lambert conformal mapping \\
Central point of the domain & $12^{\circ} \mathrm{N}, 84^{\circ} \mathrm{E}$ \\
Number of horizontal grid points & 201,161 grid points for $x, y$ respectively \\
Horizontal grid distance & $30 \mathrm{~km}$ \\
Number of vertical levels & 23 half sigma levels (full sigma levels are: $1,0.99,0.98,0.96$, \\
& $0.93,0.89,0.85,0.8,0.75,0.7,0.65,0.6,0.55,0.5,0.45,0.4$, \\
& $0.35,0.3,0.25,0.2,0.15,0.1,0.05,0.0)$ \\
Horizontal grid system & Arakawa B grid \\
Time integration scheme & Leapfrog scheme with time-splitting technique \\
Lateral boundary conditions & Nudging toward the NCEP/NCAR reanalysis \\
Radiation parameterization scheme & CCM2 \\
PBL parameterization scheme & MRF \\
Cumulus parameterization schemes & Grell \\
Microphysics & Simple ice \\
Soil model & Multi-layer soil model \\
\hline
\end{tabular}

setting these parameters to appropriate values. These include number of nests, type of convection, PBL, radiation parameterization schemes and many other options. Another advantage of this modeling system is that it is a state-of-the-art model and is under continuous development and well documented. A detailed description of the model is provided by Dudhia (1993) and Grell et al. (1995). An overview of the model used in this study is provided in Table I.

\section{Synoptic Features and Experimental Design}

The initial vortex of the storm was formed over the gulf of Thailand at 00:00 UTC of 24 October 1999. Moving westward across Malaysian Peninsula, it emerged in north Andaman Sea as a well-marked low-pressure area at 00:00 UTC of 25 October. It intensified into a deep depression by 12:00 UTC of 25 October and located near $12.5^{\circ} \mathrm{N} / 98.0^{\circ}$ E. Moving in the west of northwesterly direction it intensified into a cyclonic storm by 00:00 UTC of 26 October and centered at $13.5^{\circ} \mathrm{N} / 96.5^{\circ} \mathrm{E}$. Thereafter it moved northwestward and intensified into a severe cyclonic storm by 03:00 UTC of 27 October. By 15:00 UTC of the same day, it intensified into a very severe cyclonic storm. Moving in the same direction it further intensified into super cyclonic storm by 18:00 UTC of 28 October and located near 
$19.3^{\circ} \mathrm{N} / 87.2^{\circ}$ E. Figure 1(a) shows the satellite picture of the storm at 09:00 UTC on 28 October obtained from METEOSAT. The storm crossed Orissa coast close to south of Paradip at 05:30 UTC of 29 October. Figure 1(b) shows the satellite picture of the storm at the time of landfall also obtained from METEOSAT.

The model described in Section 2 is used to simulate the super cyclonic storm. The NCEP/NCAR reanalysis dataset $\left(2.5^{\circ} \times 2.5^{\circ}\right.$ horizontal resolution $)$ interpolated to model grids is used as initial and boundary condition for model integration. Starting from 00:00 UTC of 26 October 1999, the model is integrated up to $123 \mathrm{~h}$ producing 5-day forecast of the storm. Figure 2a gives the sea level pressure (SLP) valid at initial time of model integration. Simple interpolation of coarse resolution data into higher resolution could not reproduce the small scale features already smoothed out in large-scale reanalysis and hence need to be enhanced through data assimilation. In this study, the model is integrated for $12 \mathrm{~h}$ with analysis nudging before the start of actual forecast. In analysis nudging the model simulation is nudged to an available analysis. In this technique, an extra forcing term (known as analysis-nudging term) is added to the dynamical equations of the model. The analysis-nudging term for a particular variable is proportional to the difference between its value in the model simulation and the analysis. Analysis nudging will allow the model to generate some small-scale features during the nudging period and also the input fields will be initialized. The initialized fields after $12 \mathrm{~h}$ analysis nudging is presented in Figure 3. It shows the wind vector, temperature and specific humidity at 850 and $500 \mathrm{hPa}$. After $12 \mathrm{~h}$ analysis nudging (from $12 \mathrm{UTC} 25$ th to 00 UTC 26th), the storm is located at $13.2^{\circ} \mathrm{N} / 96.8^{\circ} \mathrm{E}$ (Figure 3a) compared to $13.0^{\circ} \mathrm{N} / 87.5^{\circ} \mathrm{E}$ (Figure 2a) in the NCEP reanalysis valid for $00 \mathrm{UTC}$ of 26th. This reduces the initial positional error of the storm as compared to the observation (best-fit). The initial vortex is also found to be little stronger in the initialized field than in the reanalysis. Temperature and humidity fields (after $12 \mathrm{~h}$ nudging) show some small-scale features that were not present in the reanalysis (figure not shown). Keeping in mind, the problem of initial vortex specification, the storm is simulated from the time it just intensified into a cyclonic storm so that the coarse resolution reanalysis (initialized with $12 \mathrm{~h}$ nudging) can represent the initial vortex reasonably.

\section{Results and Discussions}

As discussed in Section 3, the model is integrated up to $123 \mathrm{~h}$ starting from 00:00 UTC of 26 October to 03:00 UTC of 31 October 1999 (last $3 \mathrm{~h}$ is for verification of rainfall). Figure 2 presents the SLP at the initial time and day- 1 to day-5 as extracted from NCEP/NCAR reanalysis. Figure 2a shows the storm to be centered at $12.5^{\circ} \mathrm{N} / 97.5^{\circ} \mathrm{E}$ with central SLP of $1,006 \mathrm{hPa}$ compared to $1,002 \mathrm{hPa}$ in the observation. In next $72 \mathrm{~h}$ the storm moved almost in straight-line towards northwest. At 00:00 UTC of 29 October, it is centered at $19.5^{\circ} \mathrm{N} / 87.5^{\circ} \mathrm{E}$ with central SLP 1,004 $\mathrm{hPa}$ in comparison to estimated central SLP of $912 \mathrm{hPa}$. In the analysis, the storm is 

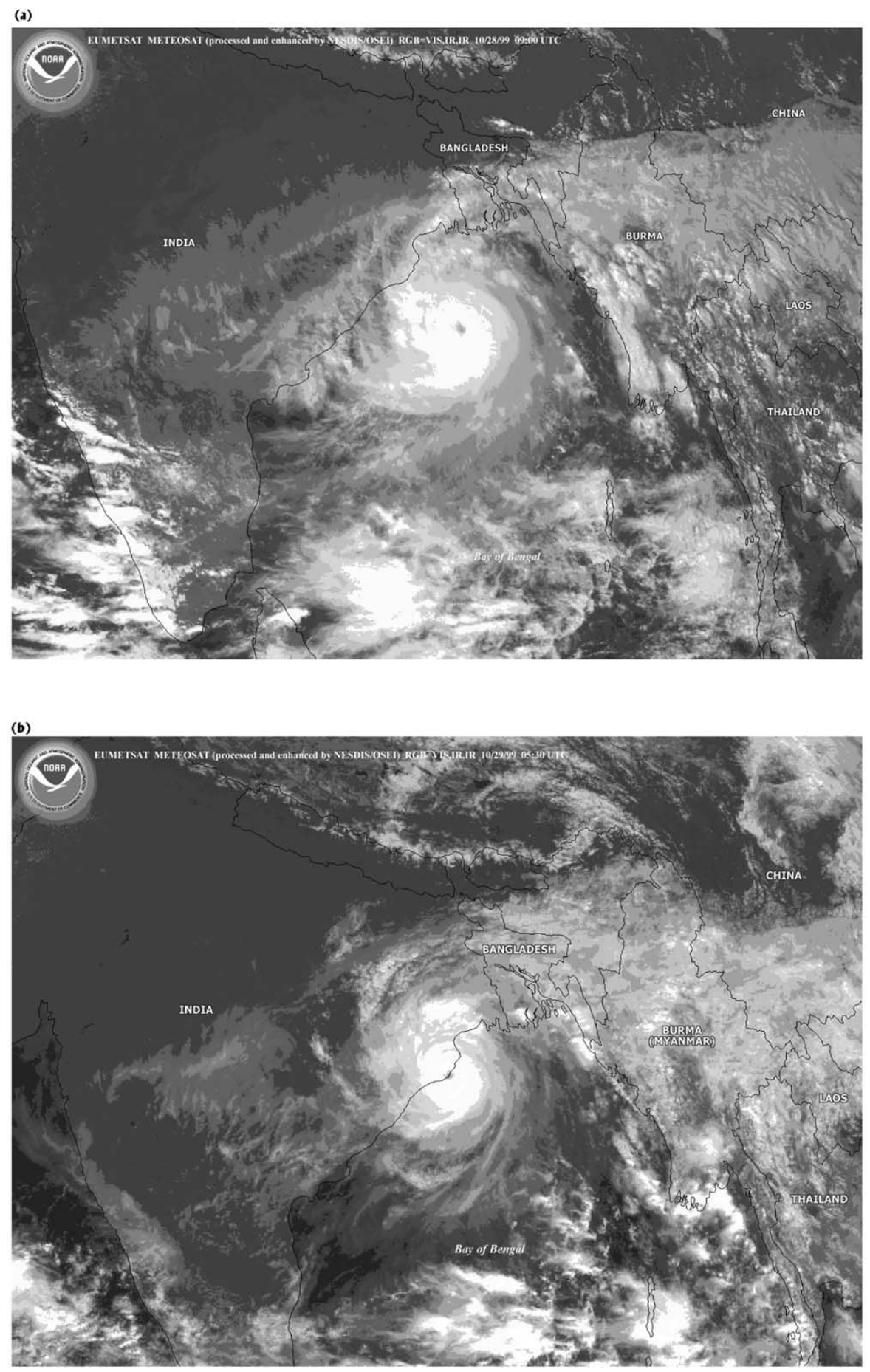

Figure 1. Satellite pictures of the storm as obtained from EUMETSAT METEOSAT. (a) at 09:00 UTC of 28 October 1999; (b) at 05:30 UTC of 29 October 1999. 
(a)

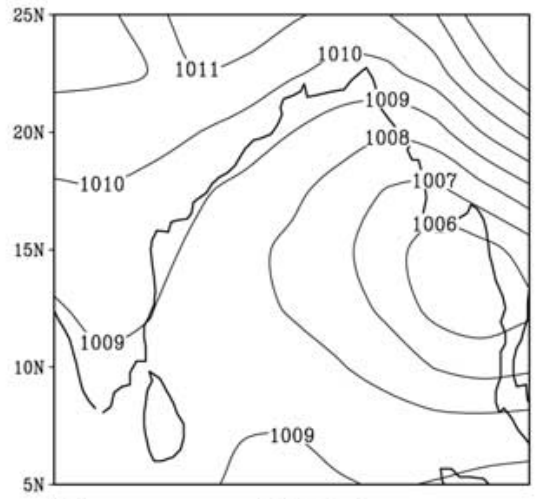

(b)

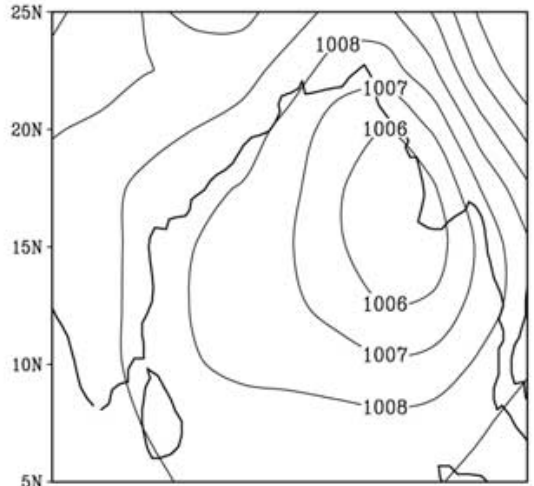

(c)

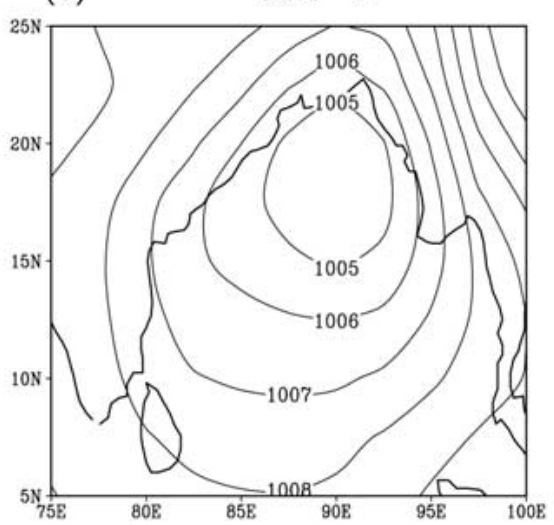

(d)

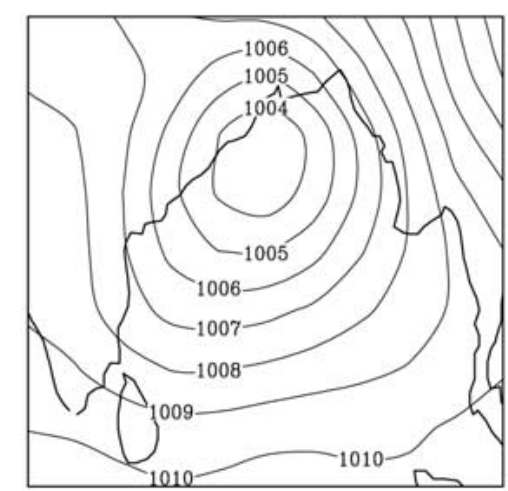

(e)

DAY -4

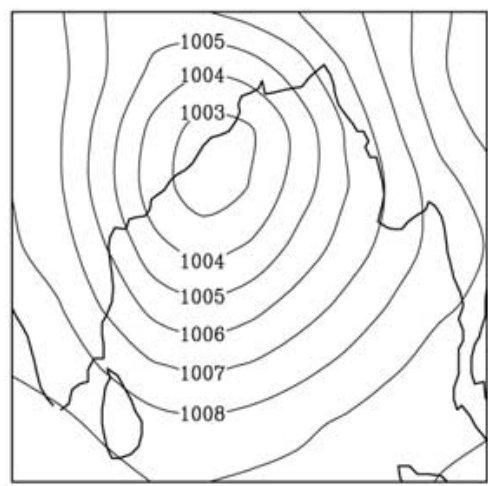

(f)

DAY -5

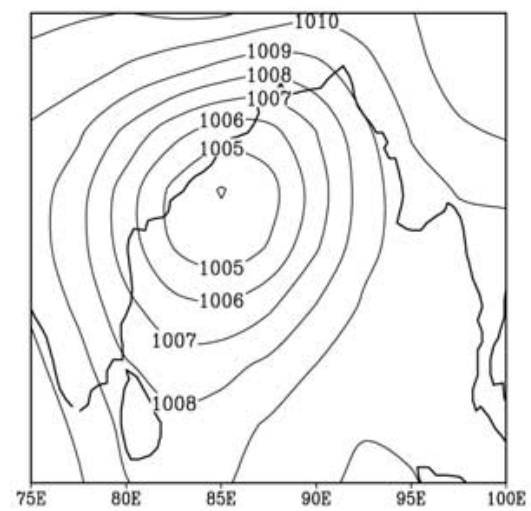

Figure 2. Mean sea level pressure as obtained from NCEP/NCAR reanalysis (all at 00:00 UTC). (a) Analysis valid on 26 October 1999. (b) Verification analysis for Day-1. (c) Verification analysis for Day-2. (d) Verification analysis for Day-3. (e) Verification analysis for Day-4. (f) Verification analysis for Day-5. 
(a)

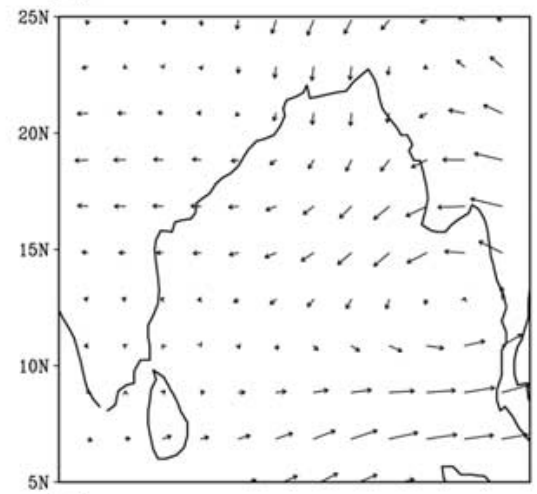

(c)

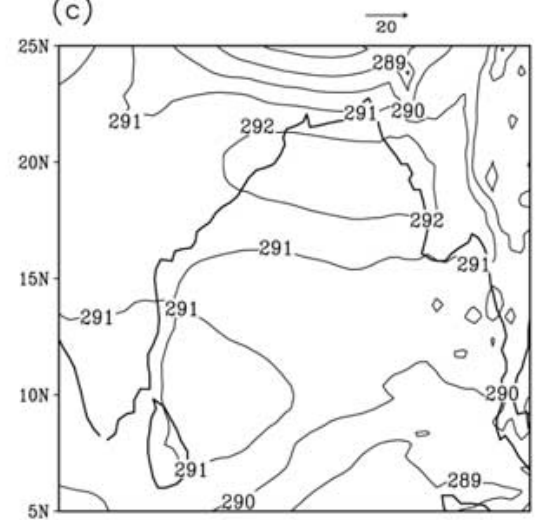

(e)

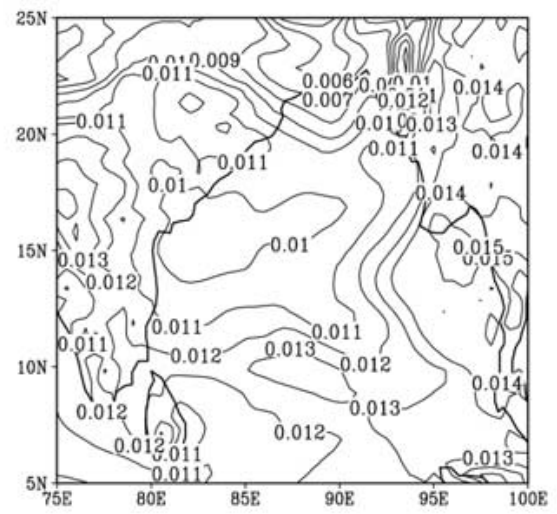

(b)

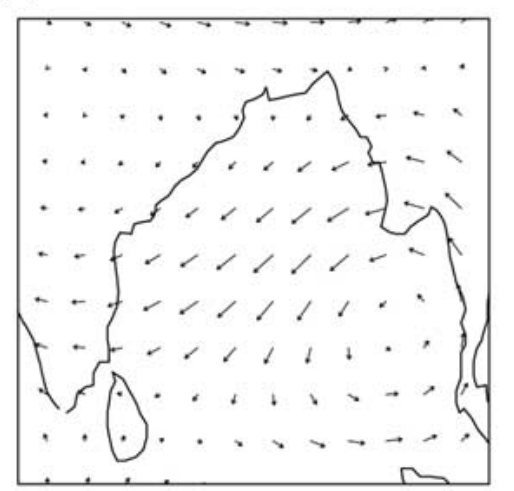

(d)

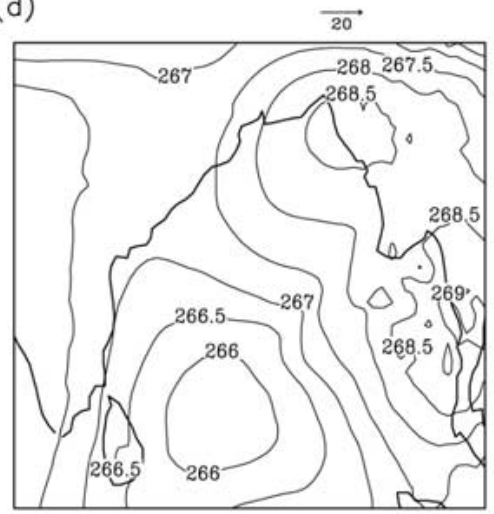

(f)

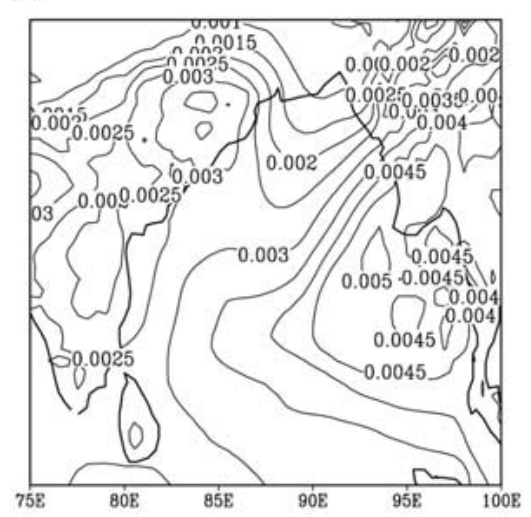

Figure 3. Initialized fields after $12 \mathrm{~h}$ analysis nudging valid at 00:00 UTC on 26th. (a) Wind at $850 \mathrm{hPa}$. (b) Wind at $500 \mathrm{hPa}$. (c) Temperature at $850 \mathrm{hPa}$. (d) Temperature at $500 \mathrm{HPa}$. (e) Specific humidity at $850 \mathrm{hPa}$. (f) Specific humidity at $500 \mathrm{hPa}$. 
found to recurve at this point and first moved to the west of southwesterly direction and then further southward. The intensity of the storm is poorly represented in the reanalysis, which is attributed to its coarse resolution. The initial and subsequent positions of the storm are also found to be in error compared to the positions in the best-fit track. Initial positional error is $155.3 \mathrm{~km}$.

\subsection{MEAN SEA LEVEL PRESSURE}

Figure 4 illustrates the sea level pressure simulated by the model. Comparison of Figures $2 \mathrm{~b}-\mathrm{f}$ with the Figures $4 \mathrm{a}-\mathrm{e}$ show that the large-scale pressure distribution pattern in the simulation is in close agreement with the analysis. Model simulation shows intense storm with strong pressure gradient where as the verification analysis shows weak storm spread over a larger area. Figure 4a shows the storm to be centered at $13.8^{\circ} \mathrm{N} / 92.5^{\circ} \mathrm{E}$ with central SLP exactly same as estimated (998 $\mathrm{hPa}$ ). The best-fit track shows the storm to be located around $15.5^{\circ} \mathrm{N} / 93.0^{\circ} \mathrm{E}$. In day-2, simulated central SLP is $985 \mathrm{hPa}$ compared to estimated central SLP of $986 \mathrm{hPa}$. The positions of the storm in model simulation and in best-fit track are $16.1^{\circ} \mathrm{N} / 89.8^{\circ} \mathrm{E}$ (Figure $4 \mathrm{~b}$ ) and $17.5^{\circ} \mathrm{N} / 90.0^{\circ} \mathrm{E}$ respectively. This indicates that the intensity of the storm is predicted almost accurately in both day-1 and day-2. Figure 4(c) illustrates day-3 forecast of SLP. The storm is centered at $18.0^{\circ} \mathrm{N} / 86.2^{\circ} \mathrm{E}$ with central SLP of $963 \mathrm{hPa}$. This shows further intensification of the storm with central pressure dropped by $22 \mathrm{hPa}$ in last $24 \mathrm{~h}$. In observation, the storm is found to be much more intense with central SLP of $912 \mathrm{hPa}$ and located around $19.6^{\circ} \mathrm{N} / 87.0^{\circ} \mathrm{E}$. In first $24 \mathrm{~h}$ the movement of the storm is slow and in the direction to the west of the actual movement. In day- 2 and day-3, the storm moved in the same direction as the best-fit but little slow. In day-4 and day-5, the storm is found to be more intense than in the observation with central SLP of 982 and $991 \mathrm{hPa}$ respectively (Figure 4d and e). This is probably due to delayed landfall simulated by the model compared to the observation.

\subsection{PRECIPITATION}

On day-1 and day-2, precipitation is confined mainly over the Ocean and could not be validated with observations. Figure 5 shows observed precipitation valid on day-3, day- 4 and day-5. Figure 6 represents the model simulated $24 \mathrm{~h}$ accumulated precipitation valid on day-3 to day-5 (over the same domain as in Figure 5) with contour interval $2 \mathrm{~cm}$. A close look at these figures show that the precipitation is reasonably well simulated by the model. On day-3, the model simulation (Figure 6a) shows precipitation of $3 \mathrm{~cm}$ and $2.5 \mathrm{~cm}$ at Balasore and Bhubaneshwar compared to $4.1 \mathrm{~cm}$ and $2.6 \mathrm{~cm}$ respectively in the observations (Figure 5a). The magnitude of maximum precipitation $(8 \mathrm{~cm})$ is found to be same as in the observation. On day- 4 and day-5 the model simulation shows very heavy precipitation over coastal Orissa. On day-4, maximum precipitation of $26 \mathrm{~cm}$ is simulated 
(a)

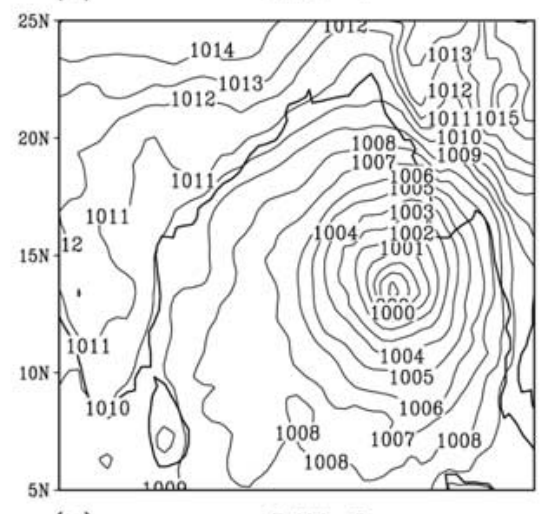

(b)

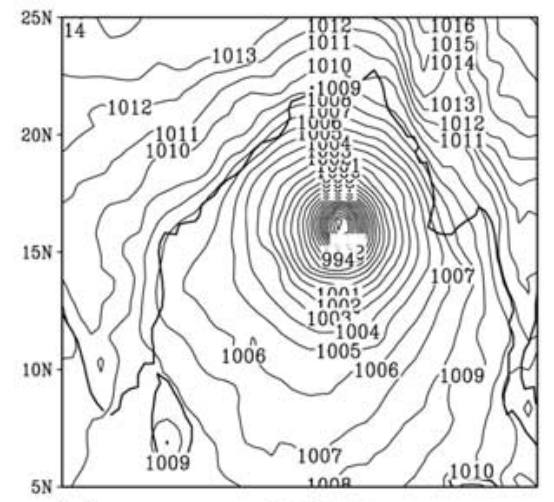

(c) (d)

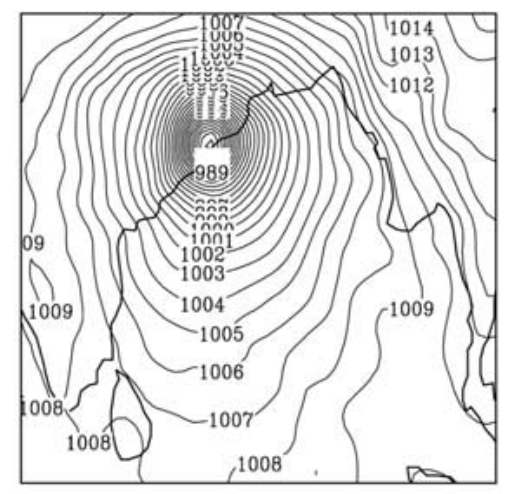

(e)

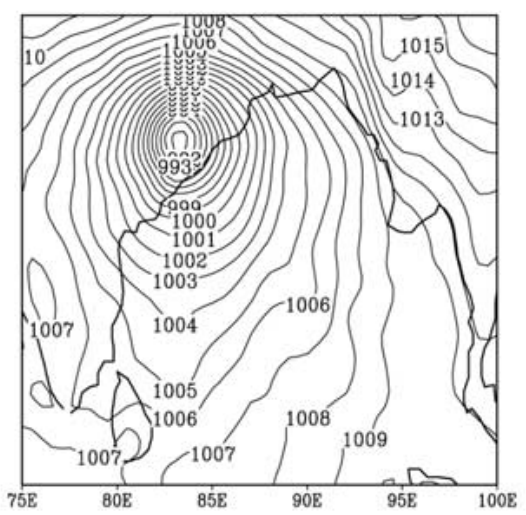

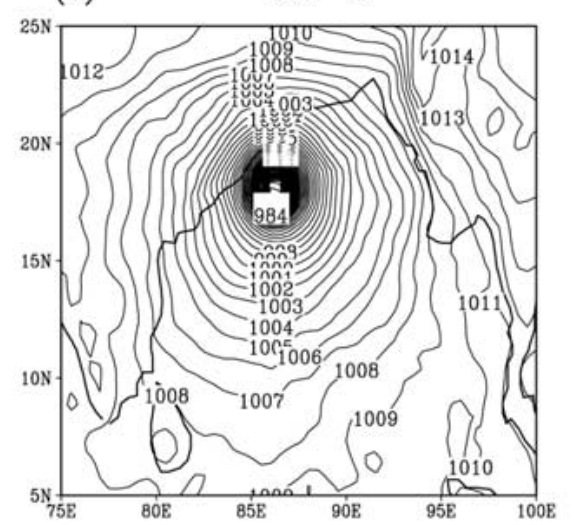

Figure 4. Model simulated sea level pressure (all at 00:00 UTC). (a) Valid on 27 October 1999. (b) Valid on 28 October 1999. (c) Valid on 29 October 1999. (d) Valid on 30 October 1999. (e) Valid on 31 October 1999. 
Table II.

\begin{tabular}{rlllll}
\hline & \multicolumn{2}{l}{ Model simulated } & & \multicolumn{2}{l}{ Estimated/Observed } \\
\cline { 2 - 3 } \cline { 5 - 6 } $\begin{array}{l}\text { Time } \\
\text { (h) }\end{array}$ & $\begin{array}{l}\text { Pressure drop } \\
(\mathrm{hPa})\end{array}$ & $\begin{array}{l}\text { Maximum } \\
\text { surface wind } \\
\text { (knots) }\end{array}$ & & $\begin{array}{l}\text { Pressure drop } \\
(\mathrm{hPa})\end{array}$ & $\begin{array}{l}\text { Maximum } \\
\text { Surface wind } \\
\text { (knots) }\end{array}$ \\
\hline 24 & 10 & 33 & 10 & 45 \\
48 & 23 & 55 & 20 & 65 \\
72 & 45 & 78 & 98 & 140 \\
96 & 25 & 51 & 14 & 65 \\
120 & 15 & 37 & 12 & 18 \\
\hline
\end{tabular}

around $20.2^{\circ} \mathrm{N} / 86.4^{\circ} \mathrm{E}$ (very close to the Bhubaneswar) compared to $42.6 \mathrm{~cm}$ in the observation at Bhubaneswar. The model simulates $25 \mathrm{~cm}$ of precipitation at Bhubaneshwar. The model simulation shows precipitation of $12 \mathrm{~cm}, 25 \mathrm{~cm}, 24 \mathrm{~cm}$, $22 \mathrm{~cm}, 16 \mathrm{~cm}$ and $18 \mathrm{~cm}$ at Balasore, Chandbali, Jaipur, Cuttack, Puri and Udala compared to $19.5 \mathrm{~cm}, 24.8 \mathrm{~cm}, 19.8 \mathrm{~cm}, 25.5 \mathrm{~cm}, 18.1 \mathrm{~cm}$ and $31.5 \mathrm{~cm}$ respectively in the observations. It indicates that the precipitation is slightly under predicted at some locations on day-4. On day-5 maximum precipitation of $39 \mathrm{~cm}$ is simulated around $21.3^{\circ} \mathrm{N} / 86.6^{\circ}$ E compared to $36.3 \mathrm{~cm}$ observed around $20.7^{\circ} \mathrm{N} / 86.8^{\circ} \mathrm{E}$. The model simulation shows precipitation of $28 \mathrm{~cm}, 16 \mathrm{~cm}, 6 \mathrm{~cm}$ and $34 \mathrm{~cm}$ at Chandbali, Cuttack, Puri and Udala respectively. IMD recorded rainfall at these locations are $34 \mathrm{~cm}, 25.2 \mathrm{~cm}, 11.8 \mathrm{~cm}$ and $12.7 \mathrm{~cm}$ respectively. This shows that although the location of maximum precipitation is not matching exactly with observation (due to error in simulated position of the storm), the overall precipitation distribution is well simulated by the model.

\subsection{WIND AT 850 hpa}

Figure 7 presents wind vector at $850 \mathrm{hPa}$ from day- 1 to day-5. The left and right panels represent verification analysis as obtained from NCEP/NCAR and model simulation respectively. A comparative study of the figures in the right panel with the corresponding figures in the left panel shows that the large-scale wind patterns are well simulated by the model. The model simulates much stronger wind around the storm compared to the analysis. In the analysis maximum winds are of the same order of 30 knots in all 5 days whereas in model simulation, the wind is becoming stronger with increasing intensity of the storm. In day-1 and day-2 (Figure $7 \mathrm{~b}$ and d), the wind is found to be stronger in the northeast sector of the storm. The verification analysis (Figure 7a and c) also shows the same feature. The verification analysis of day-3 and day-4 (Figures 7e and g) shows stronger wind in the southern sector of the storm. This feature is also well simulated by the model. 
(a)

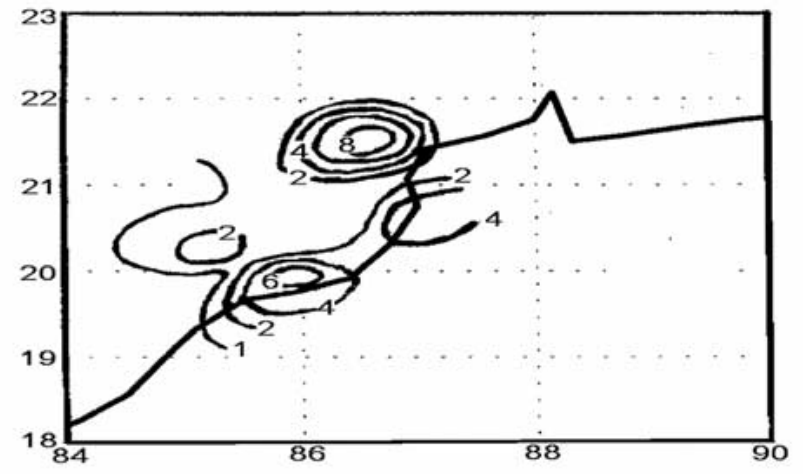

(b)

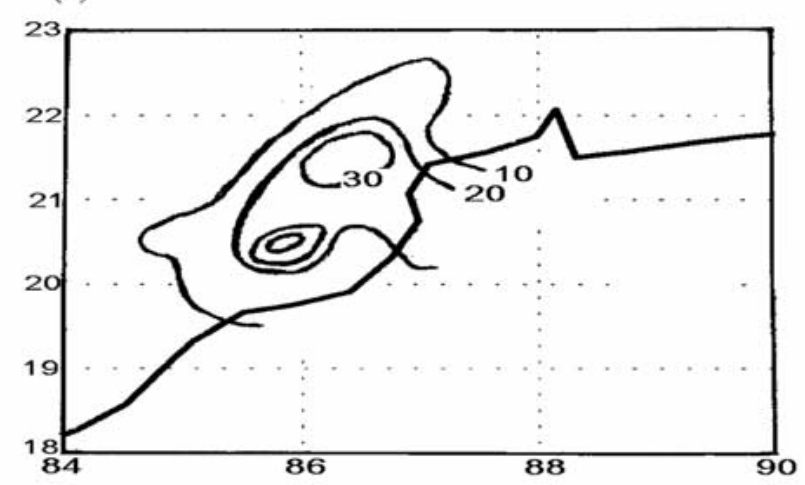

(c)

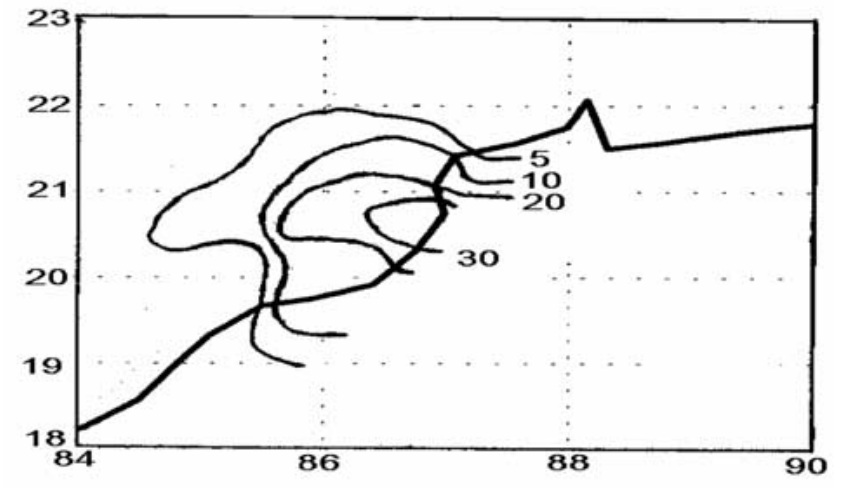

Figure 5. Observed $24 \mathrm{~h}$ accumulated rainfall as obtained from IMD (all at 03:00 UTC). (a) Valid on 29 October 1999. (b) Valid on 30 October 1999. (c) Valid on 31 October 1999. 
(a) $\mathrm{DAY}-3$

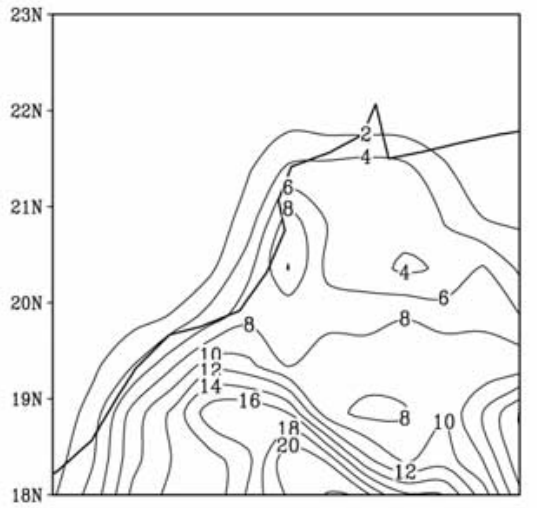

(b) $\quad \mathrm{DAY}-4$

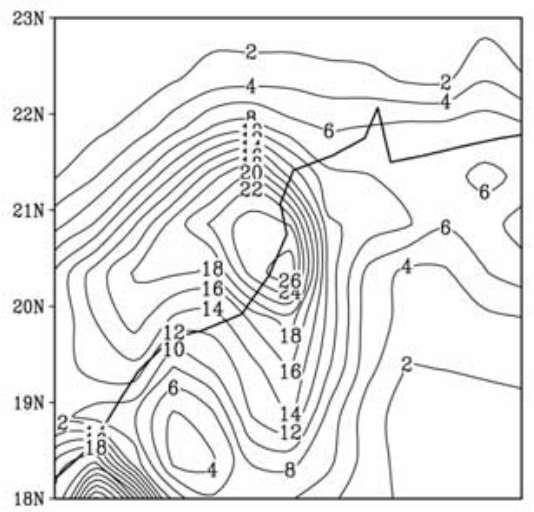

(c) DAY -5

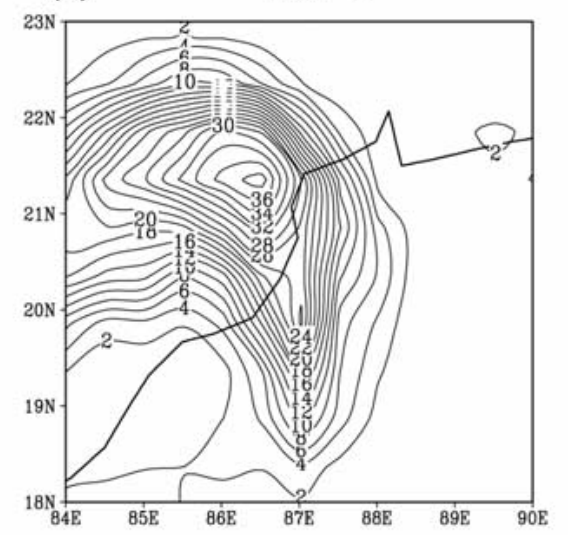

Figure 6. Model simulated $24 \mathrm{~h}$ accumulated precipitation (all at 03:00 UTC). (a) Valid on 29 October 1999. (b) Valid on 30 October 1999. (c) Valid on 31 October 1999. 

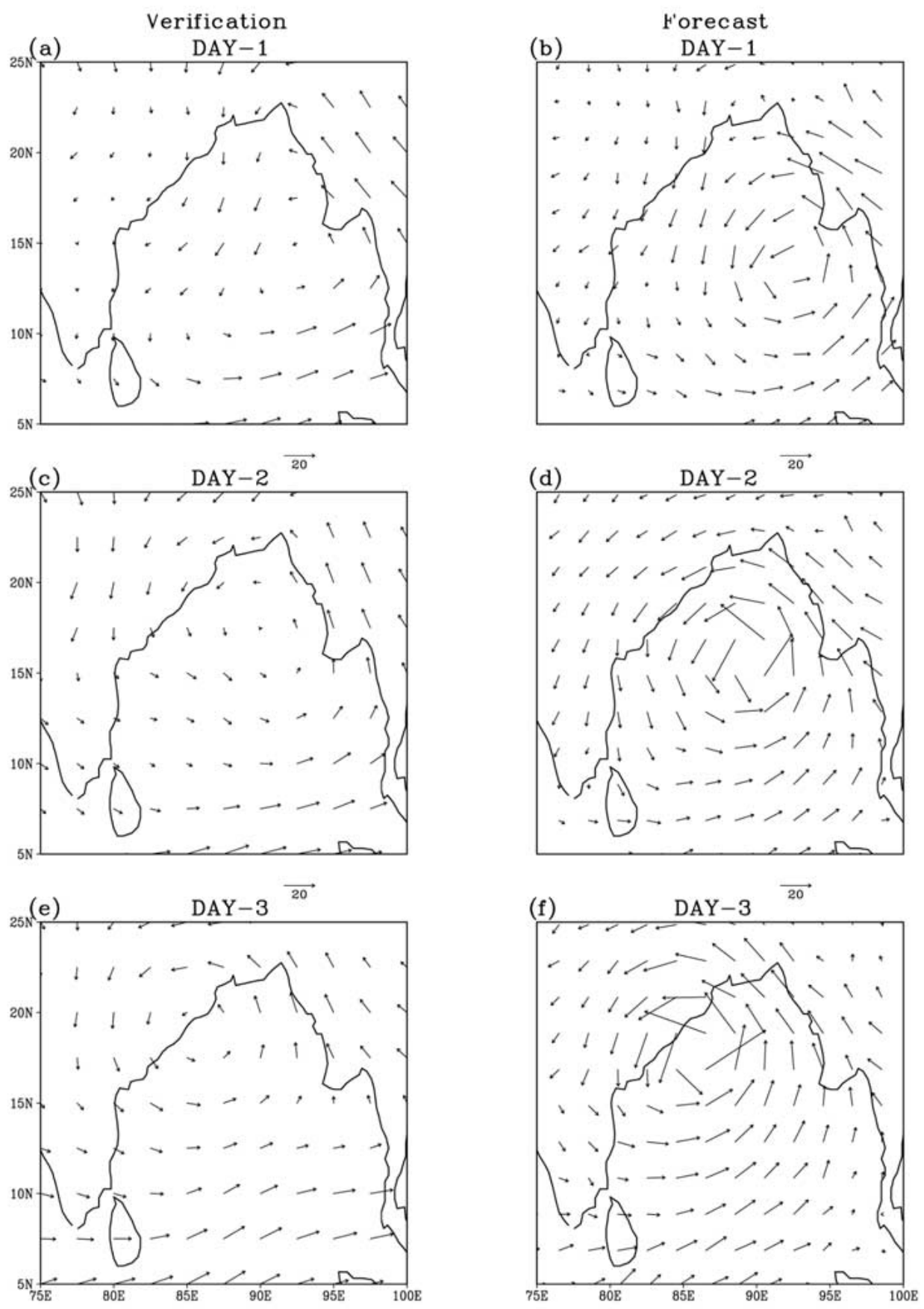

Figure 7. Wind vector at $850 \mathrm{hPa}$, verification analysis and forecasts (all at 00:00 UTC). (a) Verification analysis for Day-1. (b) Forecast valid for Day-1. (c) Verification analysis for Day-2. (d) Forecast valid for Day-2. (e) Verification analysis for Day-3. (f) Forecast valid for Day-3. (g) Verification analysis for Day-4. (h) Forecast valid for Day-4. (i) Verification analysis for Day-5. (j) Forecast valid for Day-5. 

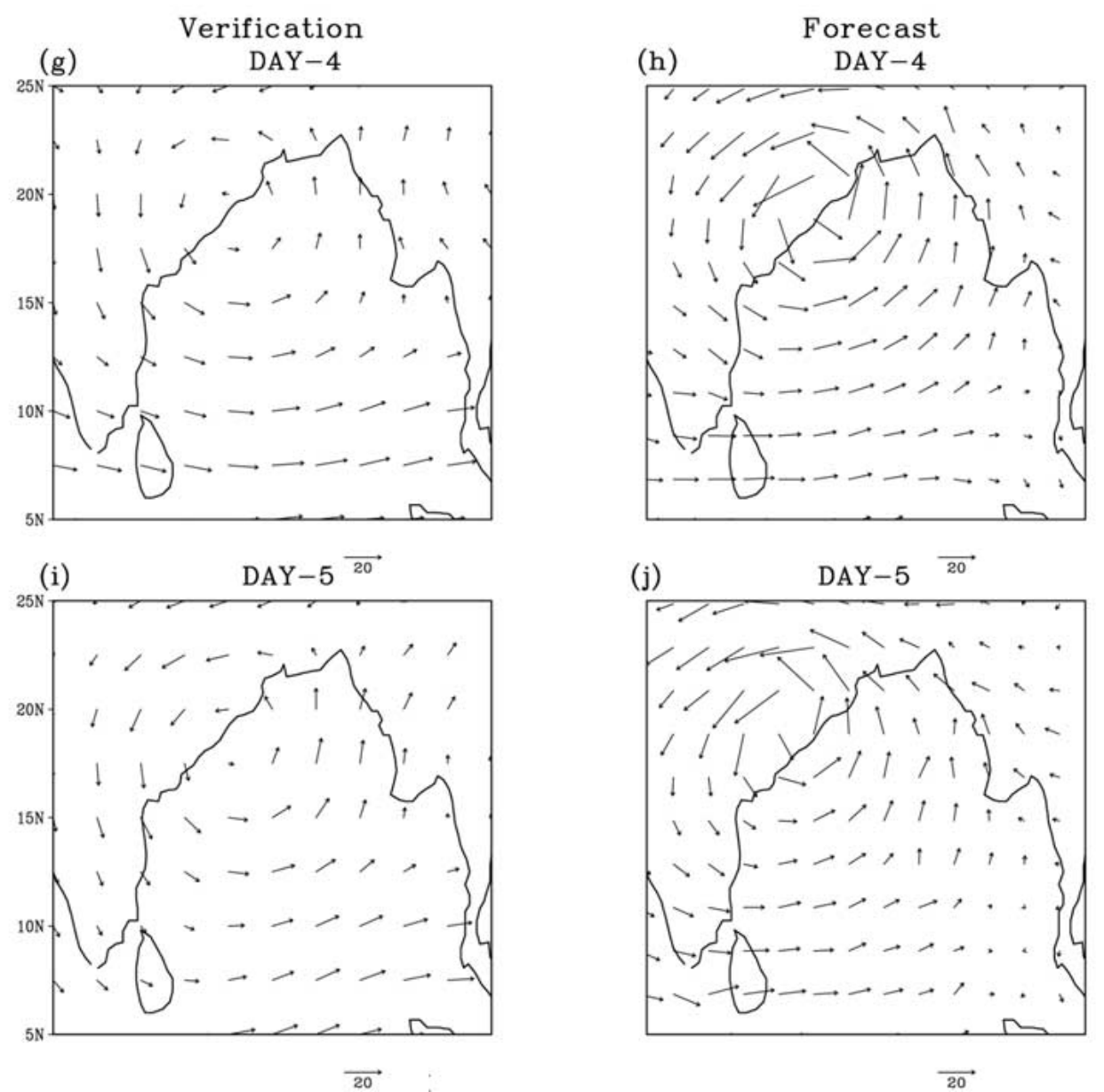

Figure 7. Continued.

The strength of surface wind (Table II) is simulated reasonably well by the model except on day-3 and day-5. In day-3 the strength is under predicted whereas it is slightly over predicted on day-5. The over prediction on day-5 is due to delayed landfall compared to the observation.

\subsection{TRACK}

The track of the cyclone obtained from model simulation is compared with the track of obtained from NCEP/NCAR reanalysis and the best-fit track obtained from IMD. Figure 8 shows the track of the cyclone with locations of the storm in every 24 h. In the best-fit track the cyclone is found to be located at $13.5^{\circ} \mathrm{N} / 96.5^{\circ} \mathrm{E}$ at 00:00 UTC of 26 October. It moved almost straight in the northwesterly direction and crossed the Orissa coast near Paradip at 05:30 UTC of 29 October. After landfall 


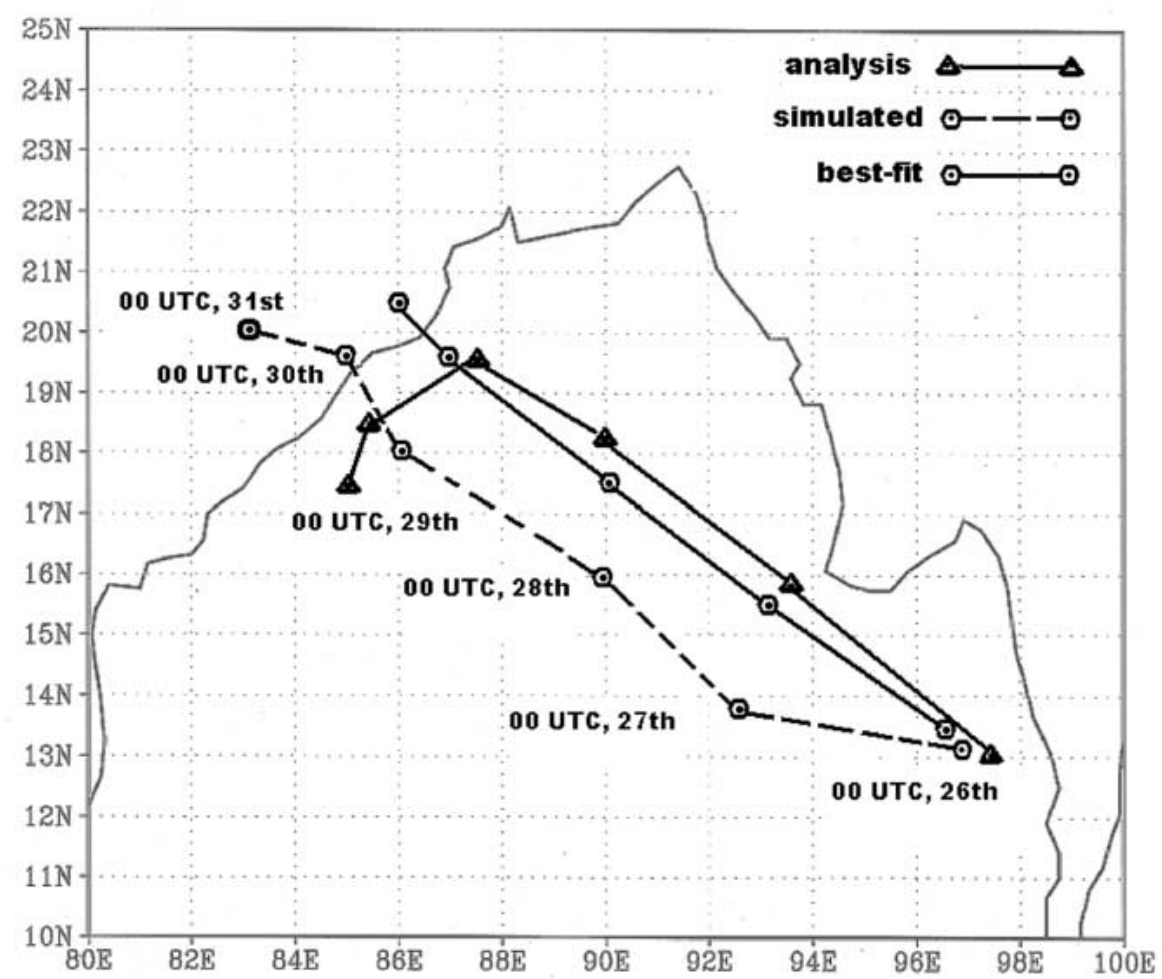

Figure 8. Track of the cyclone during 26th-31st October 1999 as obtained from IMD (best-fit track), NCEP/NCAR reanalysis and model simulation.

Table III. Vector displacement error (in $\mathrm{km}$ )

\begin{tabular}{rll}
\hline $\begin{array}{l}\text { Time } \\
\text { (h) }\end{array}$ & w.r.t Observation & w.r.t Analysis \\
\hline 24 & 196 & 247 \\
48 & 157 & 267 \\
72 & 197 & 216 \\
96 & 137 & 143 \\
120 & 302 & 318 \\
\hline
\end{tabular}

it continue to move in the same direction and located near $20.5^{\circ} \mathrm{N} / 86.0^{\circ} \mathrm{E}$ at 00:00 UTC of 30 October. It remained stationary at that location till 00:00 UTC 31 October. The model-simulated track of the storm is almost parallel to the bestfit track on day-2, day-3 and day-4. On day-1, it moved slightly to the west of the northwesterly direction. On day-5, the storm moved further westward, it is due to error in the reanalysis, which shows the storm to move southwestward and further 
south. The vector displacement errors (Table III) in the simulation are always below $200 \mathrm{~km}$ except on day-5. It is to be mentioned here that the initial positional error (after $12 \mathrm{~h}$ analysis nudging) is $122 \mathrm{~km}$ compared to the observation. The track forecast can be further improved by improving the initial vortex specification.

\section{Conclusions}

In this paper, the results of numerical simulation of Orissa super cyclone using PSU/NCAR modeling system are presented. Some broad conclusions that can be drawn out of the obtained results are as follows.

The model could be able to predict the intensity of the storm almost accurately on day- 1 and day-2. In day-3, the intensity is under predicted by the model but still showing a pressure drop of $45 \mathrm{hPa}$. This is reasonably good as far as simulation by numerical models are concerned. Intensity of the storm is over predicted in day- 4 and day-5, it is probably due to delayed landfall that causes late dissipation of the storm.

The delayed landfall could be due to the initial positional error of the storm in the reanalysis and relatively slow movement of the storm particularly on day- 2 .

Precipitation distribution and magnitude is simulated reasonably well by the model.

The model could able to predict the track of the storm with fair degree of accuracy. The error in track forecast is almost of the order initial positional error in the analysis and could be improved further by reducing initial positional error in the specification of the storm.

\section{Acknowledgments}

The authors gratefully acknowledge the NCEP/NCAR for using their reanalysis data sets for the present study. The authors also owe thanks to India Meteorological Department for providing precipitation data and the best-fit track of the storm. National Oceanic and Atmospheric Administration (NOAA) is gratefully acknowledged for providing satellite pictures of the storm. The first author also wishes to thank Council of Scientific and Industrial Research (CSIR) for providing financial support to carry out the work. This work is partially financed by Office of Naval Research (ONR) and Naval Research Laboratory, USA.

\section{References}

Braun, S. A. and Tao, W.-K.: 2000, Sensitivity of high-resolution simulations of hurricane Bob (1991) to planetary boundary layer parameterisations, Mon. Wea. Rev. 128, 3941-3961.

Chen, D. R., Yeh, T. C., Haung, K. N., Peng, M. S., and Chang. S. W.: 1995, A new operational typhoon track prediction system at the central weather Bureau in Taiwan. Preprints 21 st Conf. Hurr. Trop. Meteor, Amer. Meteor. Soc., Boston, MA 02108, pp. 50-51. 
De Angelis, D.: 1976, World of tropical cyclones - North Indian Ocean, Mar. Weather Log. 20, 191-194.

De Maria, M., Aberson, H. C., Ooyama, K. V., and Lord, S. S.: 1992, A nested spectral model for hurricane forecasting, Mon. Wea. Rev. 120, 1628-1643.

Dudhia, J.: 1993, A non-hydrostatic version of Penn State - NCAR mesoscale model: Validation tests and simulation of an Atlantic cyclone and cold front, Mon. Wea. Rev. 121, 1493-1513.

Gray, W. M.: 1968, Global view of the origin of tropical disturbances and storms, Mon. Wea. Rev. 96, 669-700.

Grell, G., Dudhia, J., and Stauffer, D. R.: 1995, A description of the fifth generation Penn State/NCAR Mesoscale Model (MM5). NCAR Tech. Note NCAR/TN-398 + STR, 122 pp.

Gupta, Akhilesh and Bansal, R. K.: 1997, Performance of a global spectral model in predicting the track of a hurricane in the Bay of Bengal using synthetic vortex, Dept. of Sci. \& Tech., New Delhi (NCMRWF) Tech. Report, August, 1997.

Holland, G. J., Leslie, L. M., Ritchie, E. A., Dietachmayer, G. S., Klink, M., and Powers, P. E.: 1991, An interactive analysis and forecasting system for tropical cyclone motion, Wea. Forecasting 6 , 415-423.

Iwasaki, T., Nakano, H., and Sugi, M.: 1987, The performance of typhoon track prediction model with cumulus parameterization, J. Meteor. Soc. Japan 65, 555-570.

Karyampudi, V. M., Lai G. S., and Manobianco, J.: 1998, Impact of initial condition, rainfall assimilation and cumulus parameterization on simulation of Hurricane Florance (1988), Mon. Wea. Rev. 126, 3077-3101.

Krishnamurti, T. N. and Oosterhof, D.: 1989, Prediction of the life cycle of a super-typhoon with a high-resolution global model, Bull. Amer. Meteor. Soc. 70, 1218-1230.

Krishnamurti, T. N., Bedi, H. S., Yap, K. S., and Oosterhof, D.: 1993, Hurricane forecast in the FSU model, Adv. Atmos. Sci. 10, 121-131.

Kurihara, Y., Bender, M. A., Tuleya, R. E., and Ross, R. J.: 1993, Hurricane forecasting with GFDL automated prediction system. Preprints 20th Conf. Hurr. Trop. Meteor., Amer. Meteor. Soc., Boston, MA 02108, pp. 323-326.

Kurihara, Y., Bender, M. A., Tuleya, R. E., and Ross, R. J.: 1995, Improvements in the GFDL hurricane prediction system, Mon. Wea. Rev. 123, 2791-2801.

Liu, Y., Zhang, D.-L., and Yau, M. K.: 1997, A multi-scale numerical simulation of hurricane Andrew (1992). Part I: Explicit simulation and verification, Mon. Wea. Rev. 125, 3073-3093.

Liu, Y., Zhang, D. -L., and Yau, M. K.: 1999, A multi-scale numerical simulation of hurricane Andrew (1992). Part-II: Kinematics and inner core structure, Mon. Wea. Rev. 127, 2597-2616.

Mandal, M., Mohanty, U. C., Potty, K. V. J., and Sarkar, A.: 2003, Impact of horizontal resolution on prediction of tropical cyclones over Bay of Bengal using a regional weather prediction model, Proc. Ind. Acad. Sci. (Earth and Planetary Sciences) 112(1), 79-93.

Mathur, M. B.: 1991, The National Meteorological Center's quasi-Lagrangian model for hurricane prediction, Mon. Wea. Rev. 109, 1419-1447.

Prasad, K.: 1990, Synthetic observations for representation of tropical cyclones in NWP data assimilation systems, Proc. International Symposium on Assimilation of Observations in Meteorology and Oceanography, Clermount-Ferrand, France, July 9-13.

Prasad, K., Singh, B. V., and Hatwar, H. R.: 1992, Objective analysis and track prediction of tropical cyclones with synthetic data, in D. R. Sikka and S. S. Singh (eds), Physical Processes in Atmospheric Models, Wiley Eastern Ltd., pp. 349-363.

Prasad, K., Rama Rao, Y. V., and Sanjib, Sen: 1997, Tropical cyclone track prediction by a high resolution limited area model using synthetic observation, Mausam 48(3), 351-366.

Puri, K., Davidson, N. E., Leslie, L. M., and Lagan, L. W.: 1992, The BMRC tropical limited area model, Aust. Meteor. Mag. 40, 81-104. 